\title{
Exploration of the hepatoprotective effect and mechanism of magnesium isoglycyrrhizinate in mice with arsenic trioxide-induced acute liver injury
}

\author{
MIAOMIAO LIU ${ }^{1}$, BIN ZHENG ${ }^{1}$, PANPAN LIU ${ }^{1}$, JIANPING ZHANG ${ }^{2}, \mathrm{XI} \mathrm{CHU}^{3}$, CHUNHUI DONG ${ }^{3}$, \\ JING SHI ${ }^{3}$, YINGRAN LIANG ${ }^{1}, \mathrm{LI} \mathrm{CHU}^{1}$, YANSHUANG LIU ${ }^{4}$ and XUE HAN ${ }^{1,5}$ \\ ${ }^{1}$ Department of Pharmacology, School of Pharmacy; ${ }^{2}$ Department of Pharmacology, School of Basic Medicine, \\ Hebei University of Chinese Medicine, Shijiazhuang, Hebei 050200; ${ }^{3}$ Department of Pharmacy, \\ The Fourth Hospital of Hebei Medical University, Shijiazhuang, Hebei 050011; ${ }^{4}$ Hebei Key Laboratory of \\ Integrative Medicine on Liver-Kidney Patterns, Institute of Integrative Medicine, College of Integrative Medicine, \\ Hebei University of Chinese Medicine, Shijiazhuang, Hebei 050200; ${ }^{5}$ Hebei Higher Education Institute \\ Applied Technology Research Center on TCM Formula Preparation, Shijiazhuang, Hebei 050091, P.R. China
}

Received December 15, 2020; Accepted March 15, 2021

DOI: $10.3892 / \mathrm{mmr} .2021 .12077$

\begin{abstract}
Arsenic trioxide (ATO)-induced hepatotoxicity limits the therapeutic effect of acute myelogenous leukemia treatment. Magnesium isoglycyrrhizinate $(\mathrm{MgIG})$ is a natural compound extracted from licorice and a hepatoprotective drug used in liver injury. It exhibits anti-oxidant, anti-inflammatory and anti-apoptotic properties. The aim of the present study was to identify the protective action and underlying mechanism of MgIG against ATO-induced hepatotoxicity. A total of 50 mice were randomly divided into five groups (n=10/group): Control; ATO; MgIG and high- and low-dose MgIG + ATO. Following continuous administration of ATO for 7 days, the relative weight of the liver, liver enzyme, histological data, antioxidant enzymes, pro-inflammatory cytokines, cell apoptosis and changes in Kelch-like ECH-associated protein 1/nuclear factor erythroid 2-related factor 2 (Keap1-Nrf2) signaling pathway were observed. MgIG decreased liver injury, decreased the liver weight and liver index, inhibited oxidative stress and
\end{abstract}

Correspondence to: Professor Yanshuang Liu, Hebei Key Laboratory of Integrative Medicine on Liver-Kidney Patterns, Institute of Integrative Medicine, College of Integrative Medicine, Hebei University of Chinese Medicine, 3 Xingyuan Road, Shijiazhuang, Hebei 050200, P.R. China

E-mail: 957708622@qq.com

Professor Xue Han, Department of Pharmacology, School of Pharmacy, Hebei University of Chinese Medicine, 3 Xingyuan Road, Shijiazhuang, Hebei 050200, P.R. China

E-mail: hanxuecc@126.com

Key words: magnesium isoglycyrrhizinate, arsenic trioxide, inflammatory, apoptosis, oxidative stress, Kelch-like ECH-associated protein 1/nuclear factor erythroid 2-related factor 2 signaling pathway decreased the activity of glutathione, superoxide dismutase and catalase, production of reactive oxygen species and levels of pro-inflammatory cytokines, including IL-1 $\beta$, IL-6 and TNF- $\alpha$. Western blotting showed a decrease in Bax and caspase-3. There was decreased cleaved caspase-3 expression and increased $\mathrm{Bcl}-2$ expression. MgIG notably activated ATO-mediated expression of Keap1 and Nrf2 in liver tissue. $\mathrm{MgIG}$ administration was an effective treatment to protect the liver from ATO-induced toxicity. MgIG maintained the level of Nrf2 in the liver and protected the antioxidative defense system to attenuate oxidative stress and prevent ATO-induced liver injury.

\section{Introduction}

Arsenic is a common constituent of the Earth's crust and has been used in traditional Chinese medicine to treat a number of diseases, such as leukemia, psoriasis, syphilis and tuberculosis $(1,2)$. Arsenic trioxide (ATO) has been the cornerstone of the treatment of acute promyelocytic leukemia (APL) and other types of hematopoietic malignancy since its first application in the 1970s at Harbin Medical University; its efficacy has been proved in clinical trials (3). The United States Food and Drug Administration approved ATO for the treatment of APL in September 2000 (4). High-dose ATO is used as an effective chemotherapy drug in the treatment of certain types of cancers; however, toxic side effects are of concern (5). ATO has been shown to be the most effective single agent for the treatment of APL, and following the co-treatment of ATO and all-trans retinoic acid, long-term survival of patients with APL has been improved to 80-90\% (6-8). An increasing number of studies have consistently shown that ATO is effective against other cancer types, including hepatocellular carcinoma, pancreatic cancer and lung cancer $(9,10)$. In past decades, clinical data have shown that excessive use of ATO causes hepatotoxicity, nephrotoxicity and cardiotoxicity (11-15). 
The liver removes toxins and drugs, but it can also be destroyed by these harmful substances $(11,16)$. Arsenic induces hepatotoxicity by oxidative stress $(17,18)$. ATO generates reactive oxygen species (ROS), including hydroxyl radicals and superoxide anions, which decrease equilibrium and disturb natural oxidation via complex redox reactions with endogenous oxidants (19). Oxidative stress occurs when pro-oxidants overpower anti-oxidants in the living organisms (20). Pro-oxidants are chemicals that can either generate ROS or compromise anti-oxidants in cells (21). A high concentration of redox signaling of ROS is commonly observed with cell damage and metabolic dysregulation, including lipid peroxidation, and permanent protein and DNA degeneration (22). Thus, the liver is the primary organ susceptible to pathological cascades of oxidative stress (23). Parenchymal cells are most vulnerable in an oxidative environment (24). In order to control the generation of ROS in the liver, both enzymatic and non-enzymatic systems are involved in maintaining redox homeostasis (25). The imbalance between ROS production and the antioxidant system is maintained by key enzymes, such as catalase (CAT), superoxide dismutase (SOD) and glutathione (GSH) $(26,27)$. Malondialdehyde (MDA) is an end product of lipid peroxidation and is used as an indicator of oxidative damage in vivo (28). In addition to the significant role of oxidative stress, many reports suggest that the activity of inflammatory cytokines and apoptotic proteins increases with the etiology of hepatotoxicity $(29,30)$. High levels of ROS act as mediators of inflammation and induce peripheral inflammation, but other studies have shown that ATO alters expression levels of pro-inflammatory cytokines, such as TNF- $\alpha$, IL-1 $\beta$ and IL-6 $(31,32)$. When antioxidant responses are overwhelmed, ROS damage to cells leads to necrosis or apoptosis, which is manifested by oxidative stress and inflammation (33). Apoptosis is characterized by well-defined features, including cellular morphological changes, activation of caspase- 3 and cleaved caspase- 3 and imbalance of Bax/Bcl-2 (34-36).

Nuclear factor erythroid 2-related factor 2 (Nrf2) is a sensitive sensor that is key to cellular defense against oxidative species and toxic damage; it inhibits oxidative stress by upregulating Nrf2-driven antioxidants (37). Previous research has shown that adropin protects against liver injury in nonalcoholic steatohepatitis via Nrf2-mediated antioxidant capacity (38). Under normal conditions, cells maintain low constitutive levels of Nrf2-target genes via the Kelch-like ECH-associated protein 1 (Keap1)-dependent E3 ubiquitin ligase complex, which directly leads to continual ubiquitination and subsequent degradation of the transcription factor Nrf2 in the cell cytoplasm $(39,40)$. Under oxidative stress, Keap1 is inactivated, leading to the release of Nrf2 from Keap1. The switching on and off of Nrf2 protects cells from free radical damage and promotes cell survival (41). Therefore, antioxidants may serve key roles in preventing ATO-induced hepatotoxicity.

Magnesium isoglycyrrhizinate (MgIG; Fig. 1) is a magnesium salt of the 18- $\alpha$ glycyrrhizic acid stereoisomer. It is a novel molecular compound extracted from licorice root (42). In China and Japan, it is used as a hepatoprotective agent and inhibits inflammation, improves liver function and stabilizes cell membranes (43). MgIG has been used as a hepatoprotective and anti-inflammatory agent in the clinical treatment of inflammatory liver disease due to its effective role in hepatitis response and liver function recovery (44). According to our previous research, MgIG ameliorates doxorubicin-induced cardiotoxicity and hepatotoxicity via anti-oxidant and anti-apoptotic mechanisms $(42,45)$. To the best of our knowledge, however, the potential effect and mechanism of MgIG on hepatotoxicity caused by ATO has not yet been reported.

The present study aimed to evaluate the protective effect and potential mechanism of MgIG on ATO-induced hepatotoxicity, including oxidative stress, inflammatory responses, apoptosis and activation of the Keap1-Nrf2 signaling pathway.

\section{Materials and methods}

Chemicals and reagents. MgIG (purity, 99.3\%) was purchased from Chia Tai Tianqing Pharmaceutical Group Co., Ltd. ATO parenteral solution was purchased from Beijing SL Pharmaceutical Co., Ltd. All other chemicals were purchased from Sigma-Aldrich (Merck KGaA) unless otherwise specified.

Animals and treatment. A total of 50 adult male KunMing mice (age, 6-7 weeks; weight, 18-22 g) were provided by Experimental Animal Center (Hebei Medical University, Shijiazhuang, China). All mice were housed in plastic cages $\left(n=10 /\right.$ cage) under standard conditions $\left(20-24^{\circ} \mathrm{C}\right)$ and $55 \pm 5 \%$ relative humidity with a 12 -h dark-light cycle environment and ad libitum access to pellet food and water. All animal experiments were approved by the Ethics Committee for Animal Experiments of Hebei University of Chinese Medicine (approval no. DWLL2020005; approval date, 9 January, 2020).

Animals were randomly divided into the following groups ( $n=10 /$ group): Control [CON, normal saline, intraperitoneal (i.p.) injection, $0.1 \mathrm{ml} / \mathrm{kg} /$ day]; ATO (i.p., $5 \mathrm{mg} / \mathrm{kg} / \mathrm{day}$ ); MgIG-alone (MgIG, i.p., $50 \mathrm{mg} / \mathrm{kg} /$ day); high-MgIG + ATO (H-MgIG, i.p., $50 \mathrm{mg} / \mathrm{kg} /$ day $\mathrm{MgIG}+5 \mathrm{mg} / \mathrm{kg}$ ATO) and low-MgIG + ATO (L-MgIG,i.p., $25 \mathrm{mg} / \mathrm{kg} /$ day $\mathrm{MgIG}+5 \mathrm{mg} / \mathrm{kg}$ ATO). The hepatotoxicity model was established via i.p. injection with ATO $(5 \mathrm{mg} / \mathrm{kg})$. The CON group received isovolumic normal saline, as previously described (46). The L-MgIG and $\mathrm{H}-\mathrm{MgIG}$ groups were given 25 and $50 \mathrm{mg} / \mathrm{kg} \mathrm{MgIG}$, respectively, followed by $5 \mathrm{mg} / \mathrm{kg}$ ATO $6 \mathrm{~h}$ later. Dose selection of ATO and MgIG was determined according to previous literature $(47,48)$. The mice were sacrificed after 7 days of continuous treatment. After 7 days, sodium pentobarbital $(50 \mathrm{mg} / \mathrm{kg})$ was used to anesthetize mice and mice were weighed on an electronic balance to the nearest milligram. Then, blood (0.5-1.2 ml) was collected by exsanguination from the abdominal aorta for biochemical analysis. Euthanasia of mice was performed by overdose with i.p. injection of sodium pentobarbital $(200 \mathrm{mg} / \mathrm{kg})$ and was confirmed by absence of respiration and heartbeat. Liver was collected for further analysis (49).

Blood collection and serum preparation. The weight was recorded for each mouse, followed by i.p. injection by sodium pentobarbital $(50 \mathrm{mg} / \mathrm{kg})$. The blood sample was collected and centrifuged at $1,500 \mathrm{x}$ g for $10 \mathrm{~min}$ at room temperature. 


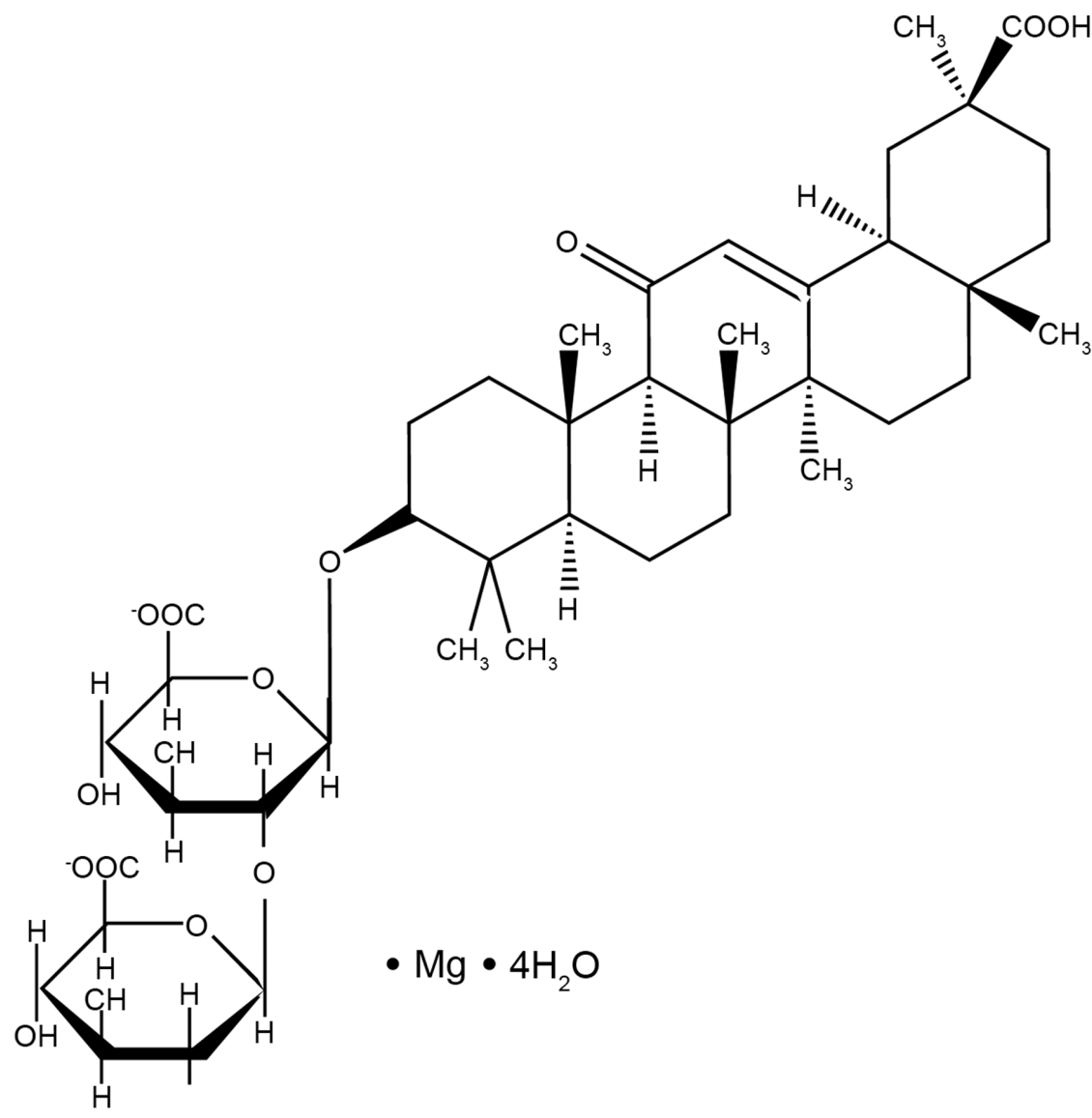

Figure 1. Chemical structure of magnesium isoglycyrrhizinate.

The serum was aspirated into clean, dry tubes and then frozen at $-20^{\circ} \mathrm{C}$ for analysis.

Liver tissue collection and homogenate preparation. Liver was removed after sacrificing the mice. The livers were weighed on an electronic balance to the nearest milligram and the relative weight of the liver was calculated using the following formula: Index weight=organ weight/body weight $\times 100 \%$. The livers were then washed with ice-cold saline and homogenized at $12,000 \mathrm{x} \mathrm{g}$ at $4^{\circ} \mathrm{C}$ for $10 \mathrm{~min}$ in PBS (pH 7.4; w/v; $1 \mathrm{~g}$ tissue with $9 \mathrm{ml} \mathrm{PBS})$. The supernatant was stored at $-20^{\circ} \mathrm{C}$ and different parameters were assayed.

Evaluation of histopathology. Livers were excised and small pieces were carefully removed from experimental animals. The tissue was dissected and fixed with ice-cold $4 \%$ paraformaldehyde overnight at $4^{\circ} \mathrm{C}$, embedded in paraffin, cut into $4 \mu \mathrm{m}$-thick slices and stained with $0.1 \%$ hematoxylin for $15 \mathrm{~min}$ and $0.5 \%$ eosin for $5 \mathrm{~min}$, both at room temperature, according to standard procedures. Pathohistological changes were observed by light microscopy (magnification, x400).

Measurement of levels of ROS. Dihydroethidium was used to monitor cellular production of ROS. Fresh liver tissue was embedded and sliced, as aforementioned. Liver tissue was incubated at $37^{\circ} \mathrm{C}$ in the dark for $1 \mathrm{~h}$. A fluorescence microscope was used to measure the nucleus of liver following staining with $5 \mathrm{mg} / \mathrm{ml}$ DAPI for $20 \mathrm{~min}$ at room temperature with an excitation source of 510-560 $\mathrm{nm}$ and an emission wavelength of $590 \mathrm{~nm}$. ROS generation was visualized and analyzed using a high-content screening system (Leica DM4000B; Leica Microsystems GmbH). ROS production was quantified using Image-Pro Plus 6.0 software (Media Cybernetics, Inc.). All experiments were repeated at least three times.

Detection of biochemical indices in serum. Aspartate aminotransferase (AST) and alanine aminotransferase (ALT) are significant predictors of liver injury (50). The serum activity of ALT (cat. no. C010-3-1), AST (cat. no. C009-3-1), SOD (cat. no. C001-3-2) and CAT (cat. no. C007-1-1), GSH (cat. no. C006-2-1), as well as the level of MDA (cat. no. C003-1-2) were detected by commercial kits according to the manufacturer's instructions (all Nanjing Jiancheng Bioengineering Institute).

Quantification of levels of $I L-1 \beta, I L-6$ and TNF- $\alpha$. The levels of IL-1 $\beta$ (cat. no. 88-7013-88), IL-6 (cat. no. 88-7064-88) and TNF- $\alpha$ (cat. no. 88-7324-88) were measured and calculated using ELISA kits, according to the manufacturers' instructions (all Thermo Fisher Scientific, Inc.).

Reverse transcription-quantitative $(R T-q) P C R$. Total RNA was extracted from liver using TRIzol ${ }^{\circledR}$ reagent (cat. no. G3013; Wuhan Servicebio Technology Co., Ltd.). RT was performed using a TIANScript RT kit (cat. no. G3330-100; Wuhan 
Servicebio Technology Co., Ltd.) according to the manufacturer's instructions. The gene expression levels of IL-1, IL-6 and TNF- $\alpha$ in liver tissue were assessed via RT-qPCR using SYBR Green (cat. no. G3320; Wuhan Servicebio Technology Co., Ltd.). The PCR conditions were as follows: Initial denaturation at $95^{\circ} \mathrm{C}$ for $15 \mathrm{~min}$, denaturation at $95^{\circ} \mathrm{C}$ for $10 \mathrm{sec}$, followed by annealing at $58^{\circ} \mathrm{C}$ for $30 \mathrm{sec}$ and extension at $72^{\circ} \mathrm{C}$ for $30 \mathrm{sec}$ for 40 cycles. Relative gene expression profiles were determined by normalization of expression to that of the housekeeping gene ( $\beta$ actin) using the $2^{-\Delta \Delta \mathrm{Cq}}$ method (51). Mouse primer sequences were as follows: IL-1 $\beta$ forward, 5'-GGTCAAAGG TTTGGAAGCAG-3' and reverse, 5'-TGTGAAATGCCACCT TTTGA-3'; IL-6 forward, 5'-ACCAGAGGAAATTTTCAA TAGGC-3' and reverse, 5'-TGATGCACTTGCAGAAAA CA-3'; TNF- $\alpha$ forward, 5'-AGGGTCTGGGCCATAGAA CT-3' and reverse, 5'-CCACCACGCTCTTCTGTCTAC-3'; and $\beta$ actin forward, 5'-CCTAGACTTCGAGCAAGAGA-3' and 5'-reverse GGAAGGAAGGCTGGAAGA-3'.

Evaluation of expression levels of Bax, Bcl-2, caspase-3, cleaved-caspase-3, Keapl and Nrf2. In order to extract total protein, liver tissue was homogenized in RIPA lysis buffer (Wuhan Servicebio Technology Co., Ltd.) and then centrifuged $12,000 \mathrm{x} \mathrm{g}$ for $10 \mathrm{~min}$ at $4^{\circ} \mathrm{C}$ to prepare a supernatant. The proteins were quantified using the bicinchoninic acid method. Equivalent amounts of protein $(50 \mu \mathrm{g})$ were resolved via $12 \%$ SDS-PAGE and transferred onto PVDF membranes and blocked in 5\% skimmed milk at room temperature for $1 \mathrm{~h}$. Membranes were incubated with the following primary antibodies (all 1:1,000) at $4^{\circ} \mathrm{C}$ for $12 \mathrm{~h}$ : Anti-Bax (cat. no. GB11690; Wuhan Servicebio Technology Co., Ltd.), anti-Bcl-2 (cat. no. PAA778Mu01; Wuhan Servicebio Technology Co., Ltd.), anti-caspase-3 (cat. no. 66470-2-lg; ProteinTech Group, Inc.), anti-cleaved caspase-3 (cat. no. 9664; Cell Signaling Technology, Inc.), anti-Keap1 (cat. no. 10503-2-ap; ProteinTech Group, Inc.), anti-Nrf2 (cat. no. 16396-1-ap; ProteinTech Group, Inc.) and anti $\beta$-actin (cat. no. 66470-2-lg; Wuhan Servicebio Technology Co., Ltd.). Next, the membranes were washed three times with TBS- $0.1 \%$ Tween-20, followed by incubation at room temperature for $1 \mathrm{~h}$ with horseradish peroxidase-conjugated secondary antibody (1:3,000; cat. no. GB23303; Wuhan Servicebio Technology Co., Ltd.), and washing three times. The proteins were visualized using an ECL Detection reagent (TransGen Biotech Co., Ltd.) and imaged using a Tanon-1600 Gel Image Analysis system (Tanon Science and Technology Co., Ltd.). Densitometry was performed using Tanon Gis 1D software (4.00; Tanon Science and Technology Co., Ltd.). All experiments were repeated three times.

TUNEL assay. TUNEL staining was performed using an in-situ cell death detection kit (cat. no. WLA029; Wanleibio Co., Ltd.) according to the manufacturer's protocol. After the liver was removed, tissues were fixed in $4 \%$ paraformaldehyde for $24 \mathrm{~h}$ at room temperature, embedded in paraffin and cut into 5- $\mu \mathrm{m}$ thick sections. Liver sections were deparaffinized, dehydrated using increasing concentrations of alcohol, washed in distilled water followed by PBS and deproteinized using proteinase $\mathrm{K}(20 \mu \mathrm{g} / \mathrm{ml})$ at $37^{\circ} \mathrm{C}$ for $30 \mathrm{~min}$. Subsequently, sections were rinsed and incubated with the TUNEL reagent at $37^{\circ} \mathrm{C}$ for $1 \mathrm{~h}$. Following rinsing, the sections were visualized using peroxidase-conjugated anti-fluorescein antibody (contained in the TUNEL kit) with $0.02 \%$ 3,3-diaminobenzidine at room temperature for $5 \mathrm{~min}$ and then counterstained with $0.5 \%$ hematoxylin (cat. no. H8070; Beijing Solarbio Science \& Technology Co., Ltd.) at room temperature for 10-30 sec. Neutral balsam was used to bond the slides and cover glass together. A total of five randomly selected microscopic fields of view were selected in order to analyze the staining results, and micrographs were scanned at $\times 400$ magnification with a digital light microscope system (Olympus Corporation; DP73).

Statistical analysis. Statistical analysis was performed using Origin Pro version 9.1 software (OriginLab Corporation.). Data are presented as the mean \pm SEM. Each experiment was repeated more than three times. Comparisons were analyzed via one-way ANOVA followed by post hoc Tukey's test. $\mathrm{P}<0.05$ was considered to indicate a statistically significant difference.

\section{Results}

Effect of MgIG on ALT and AST levels. ATO group exhibited markedly higher liver weight and index and ALT and AST activity compared with the $\mathrm{CON}$ and $\mathrm{MgIG}$ groups $(\mathrm{P}<0.01$; Fig. 2A; Table I). MgIG treatment decreased the liver index and activity of ALT and AST compared with the ATO group $(\mathrm{P}<0.05$ or $\mathrm{P}<0.01)$.

Effect of MgIG on liver histopathology. Histopathological data are shown in Fig. 2B and C. Liver tissue of mice in the CON and MgIG groups exhibited a normal structure. Severe pathological changes were observed in liver sections in the ATO group, including extensive hepatocyte vacuolation, disorganization of the parenchyma and dilatation of intrahepatocyte spaces. Furthermore, masses of acidophilic material were observed next to the central vein and microvesicular vacuolization was observed near the portal triad. Comparison of the histological features in mice from the ATO, H-MgIG and L-MgIG groups showed that pretreatment with MgIG diminished infiltration of inflammatory cells and vacuolation of hepatocytes.

Effect of MgIG on ROS production. The effect of MgIG on ATO-induced liver injury was evaluated via fluorescence of a dihydroethidium probe to assessing liver tissue production of ROS. ATO group exhibited significantly increased production of ROS compared with CON ( $\mathrm{P}<0.01$; Fig. $3 \mathrm{~A}$ and B). However, the levels of ROS in H-MgIG and L-MgIG groups decreased significantly compared with ATO group $(\mathrm{P}<0.05$ or $\mathrm{P}<0.01)$. These data indicated that MgIG suppressed ATO-induced hepatic ROS overproduction.

Effects of MgIG on activity of antioxidant enzymes. ATO caused a prominent decrease in CAT, GSH and SOD activity compared with the CON and MgIG groups. Treatment with H-MgIG and L-MgIG ( 25 or $50 \mathrm{mg} / \mathrm{kg}$ ) elevated the activity of GSH, SOD and CAT in serum compared with the ATO group $(\mathrm{P}<0.01$; Fig. 3C-F). Additionally, treatment with ATO increased MDA concentration, whereas MgIG significantly reversed this effect $(\mathrm{P}<0.05$ or $\mathrm{P}<0.01)$. 
Table I. Effect of MgIG on body weight and relative liver weight in mice.

\begin{tabular}{lrrrrr}
\hline Parameter & CON & ATO & MgIG & H-MgIG & L-MgIG \\
\hline Final body weight, g & $30.78 \pm 0.72$ & $29.71 \pm 0.91$ & $30.05 \pm 0.63$ & $29.13 \pm 1.05$ & $29.02 \pm 0.78$ \\
Liver weight, g & $1.31 \pm 0.05$ & $3.43 \pm 0.09^{\mathrm{a}}$ & $1.19 \pm 0.04^{\mathrm{b}}$ & $1.78 \pm 0.08^{\mathrm{b}}$ & $2.36 \pm 0.03^{\mathrm{b}}$ \\
Liver index, \% & $4.27 \pm 0.20$ & $11.54 \pm 0.43^{\mathrm{a}}$ & $3.94 \pm 0.10^{\mathrm{b}}$ & $6.13 \pm 0.35^{\mathrm{b}}$ & $8.18 \pm 0.30^{\mathrm{b}}$
\end{tabular}

Data are presented as the mean \pm SEM $(\mathrm{n}=10)$. ${ }^{\mathrm{a}} \mathrm{P}<0.01$ vs. $\mathrm{CON},{ }^{\mathrm{b}} \mathrm{P}<0.01 \mathrm{vs}$. ATO. MgIG, magnesium isoglycyrrhizinate; ATO, arsenic trioxide; CON, control; H-, high; L-, low.
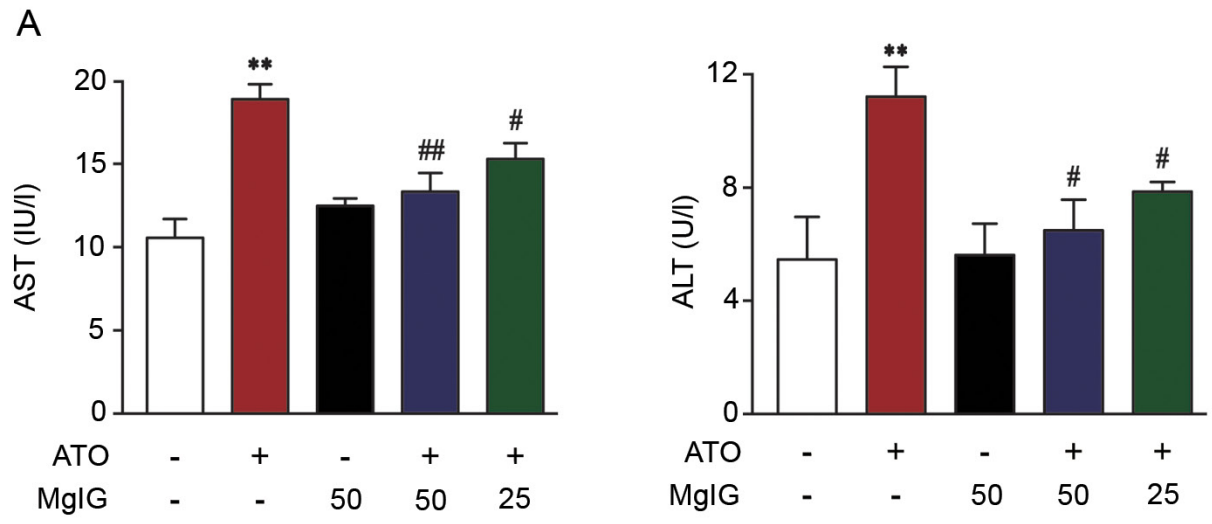

B

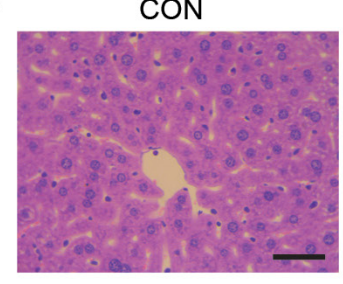

C

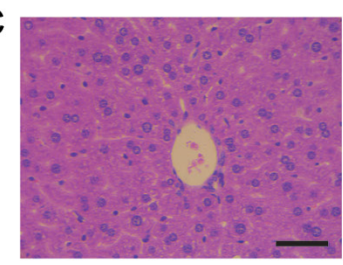

ATO
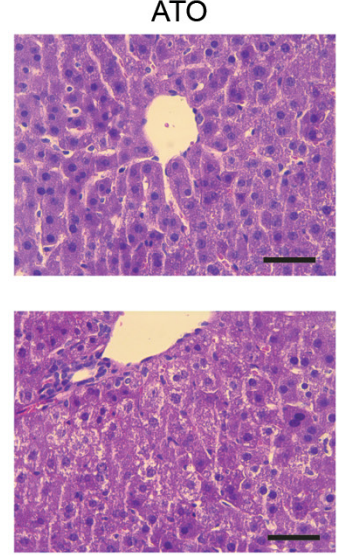
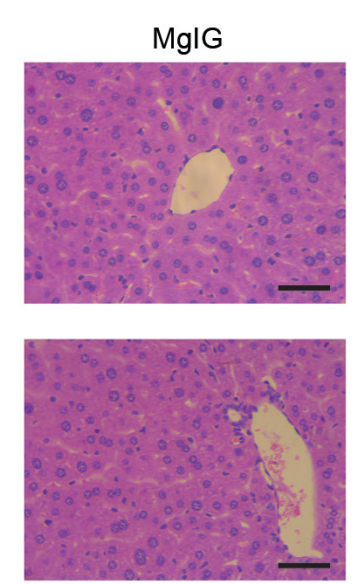
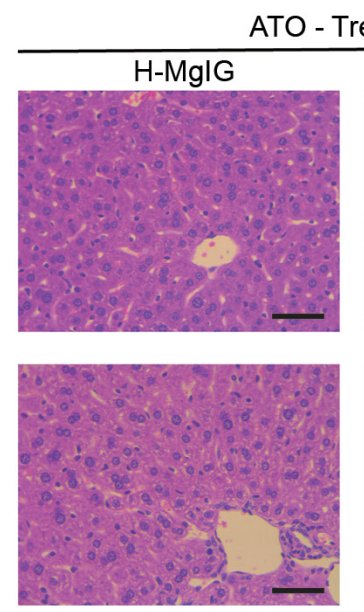

25

Figure 2. Effect of MgIG on liver injury. (A) AST and ALT activity. Representative sections of hematoxylin-eosin staining in the hepatic (B) central vein and (C) duct area (magnification, $\mathrm{x} 400$ ). Scale bar, $50 \mu \mathrm{m}$. CON showed normal hepatocyte architecture; ATO showed inflammation, hepatocyte vacuolation and necrosis/disorganization of the parenchyma. These symptoms decreased following $\mathrm{MgIG}$ treatment. Data are presented as the mean $\pm \mathrm{SEM}(\mathrm{n}=10){ }^{* *} \mathrm{P}<0.01 \mathrm{vs}$. CON, ${ }^{\#} \mathrm{P}<0.05$ and ${ }^{\# \#} \mathrm{P}<0.01$ vs. ATO. AST, aspartate aminotransferase; ALT, alanine aminotransferase; MgIG, magnesium isoglycyrrhizinate; CON, control; ATO, arsenic trioxide; H-, high; L-, low.

Effect of MgIG on IL-1 $\beta, I L-6$ and TNF- $\alpha$ expression levels. In order to assess the protective effect of MgIG, the levels of IL-1 $\beta$, IL- 6 , and TNF- $\alpha$ were measured. Levels of IL- $1 \beta$, IL- 6 , and TNF- $\alpha$ in the ATO group were significantly higher than those in the CON group $(\mathrm{P}<0.01$; Fig. $4 \mathrm{~A})$. Treatment with $\mathrm{MgIG}$ $(25$ or $50 \mathrm{mg} / \mathrm{kg}$ ) inhibited IL-1 $\beta$, IL- 6 and TNF- $\alpha$ expression $(\mathrm{P}<0.01)$. These results revealed that $\mathrm{MgIG}$ attenuated IL-1 $\beta$, IL- 6 and TNF- $\alpha$ expression levels.

mRNA expression levels of proinflammatory cytokines, such as IL-6, IL-1 $\beta$ and TNF- $\alpha$, significantly increased in the liver of ATO mice compared with the CON group $(\mathrm{P}<0.01$; Fig. 4B). Compared with the ATO group, the levels of IL-6,
IL-1 $\beta$ and TNF- $\alpha$ in H-MgIG and L-MgIG groups was significantly decreased $(\mathrm{P}<0.01)$.

Effect of MgIGon Bax,Bcl-2, caspase-3 and cleaved-caspase-3 expression levels. Western blotting was performed on liver tissue to detect the expression levels of Bax, Bcl-2, caspase-3 and cleaved-caspase- 3 to assess the effect of $\mathrm{MgIG}$ against ATO-induced hepatotoxicity. Apoptosis induced by ATO was significantly increased compared with the CON group $(\mathrm{P}<0.01$; Fig. 5). Compared with the CON group, caspase-3, cleaved-caspase-3 and Bax expression levels were increased and $\mathrm{Bcl}-2$ expression was significantly decreased in the ATO 
A
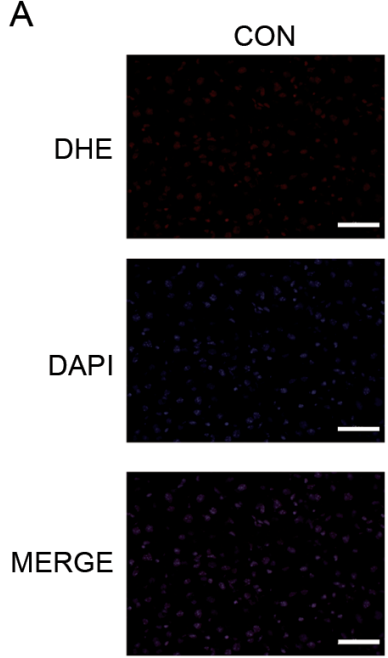

B

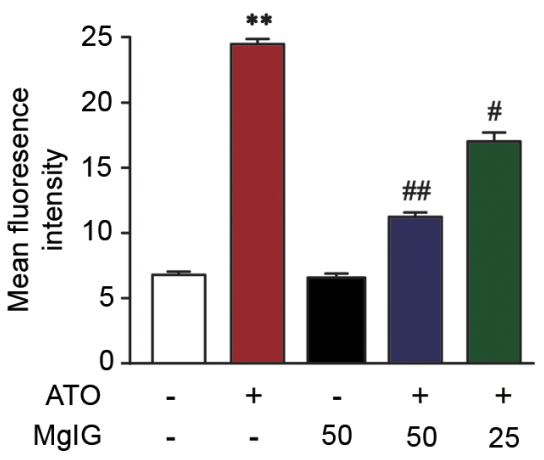

$\mathrm{E}$

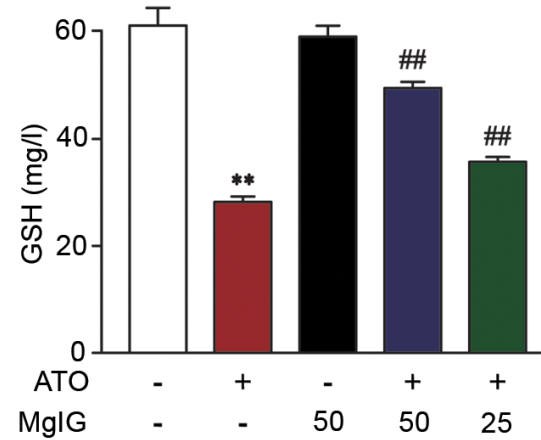

ATO
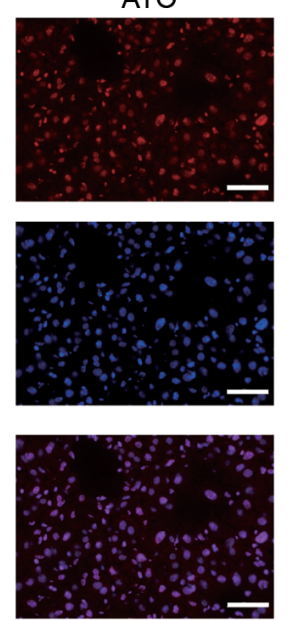

C
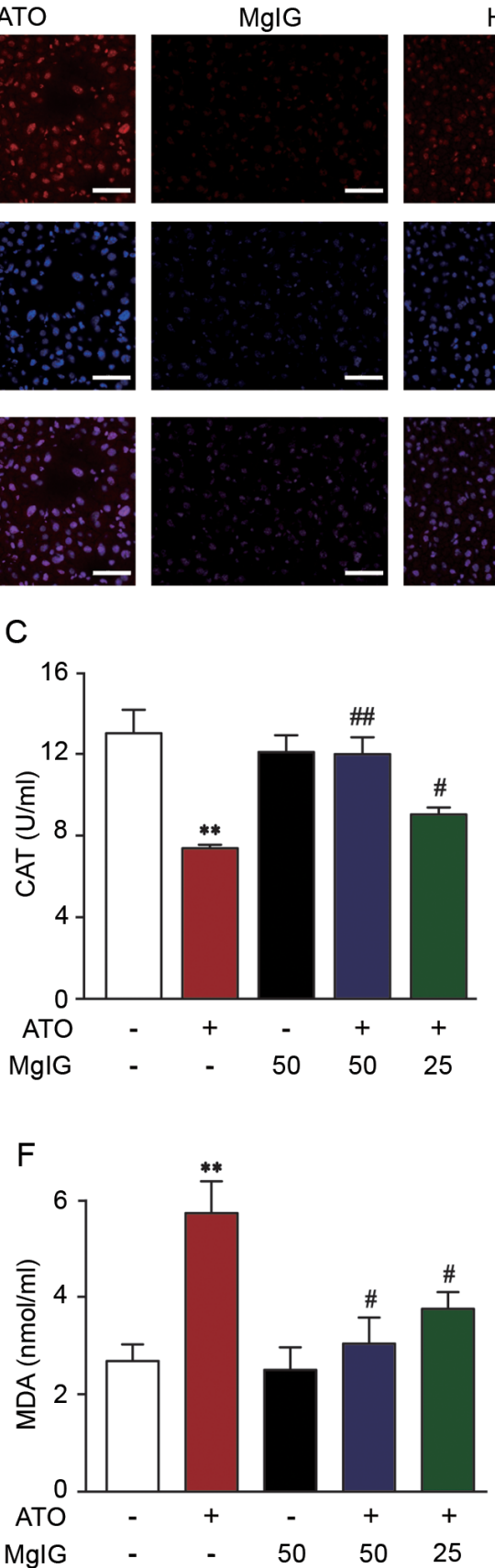

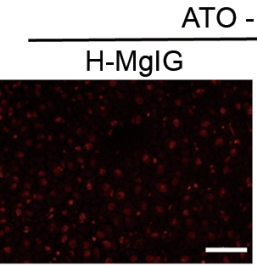

ATO - Treatment
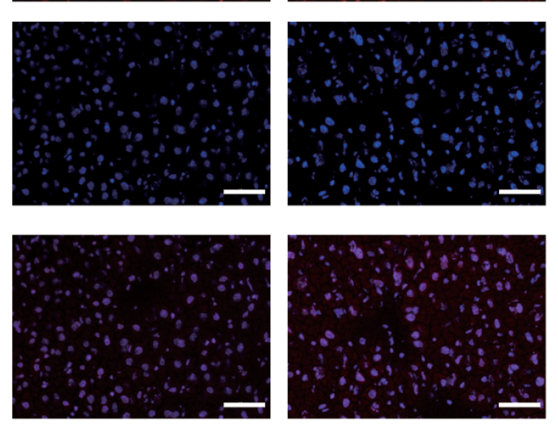

D

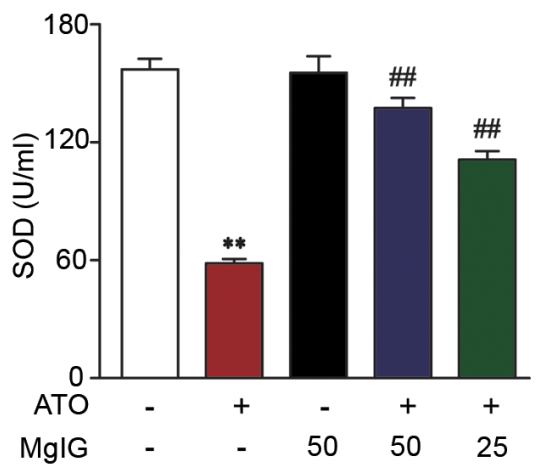

Figure 3. Effect of MgIG on ATO-induced oxidative stress. (A) Representative images and (B) quantitative analysis of reactive oxygen species levels. Activity of (C) CAT, (D) SOD, (E) GSH and (F) MDA. Data are presented the mean \pm SEM (n=10). ${ }^{* *} \mathrm{P}<0.01$ vs. CON, ${ }^{\#} \mathrm{P}<0.05$ and ${ }^{\# \#} \mathrm{P}<0.01 \mathrm{vs}$. ATO. MgIG, magnesium isoglycyrrhizinate; ATO, arsenic trioxide; CAT, catalase; SOD, superoxide dismutase; GSH, glutathione; MDA, malonaldehyde; H-, high; L-, low; DHE, dihydroethidium.

group $(\mathrm{P}<0.01)$. Compared with the ATO group, treatment with MgIG ( 25 or $50 \mathrm{mg} / \mathrm{kg}$ ) inhibited Bax, caspase- 3 and cleaved-caspase- 3 expression and increased $\mathrm{Bcl}-2$ expression $(\mathrm{P}<0.05$ or $\mathrm{P}<0.01)$. These results revealed that MgIG could reduce apoptosis in ATO-induced liver injury.

Effect of MgIG on TUNEL staining. Apoptosis in hepatic cells remained at consistently low levels in the CON group (Fig. 6). However, TUNEL-positive hepatic cells showed a significant increase in the ATO group $(\mathrm{P}<0.01)$. Both $\mathrm{H}-\mathrm{MgIG}$ and L-MgIG inhibited this effect $(\mathrm{P}<0.01)$.
Effect of MgIG on Keap1-Nrf2 expression. The protein expression of Keap1 in ATO-induced mice significantly increased compared with the CON group $(\mathrm{P}<0.01$; Fig. $7 \mathrm{~A}$ and $\mathrm{C})$. Treatment with MgIG ( 25 or $50 \mathrm{mg} / \mathrm{kg}$ ) significantly decreased expression levels of Keap1 in the liver of ATO-induced mice $(\mathrm{P}<0.05)$. ATO decreased Nrf2 expression compared with the CON group $(\mathrm{P}<0.01$; Fig. $7 \mathrm{~B}$ and $\mathrm{D})$, but there were no significant changes in the MgIG-alone group compared with the CON group. Nrf2 expression was increased following treatment with 25 or $50 \mathrm{mg} / \mathrm{kg} \mathrm{MgIG}$, which suggested that Nrf2 expression was upregulated $(\mathrm{P}<0.05$ or $\mathrm{P}<0.01)$. 
A

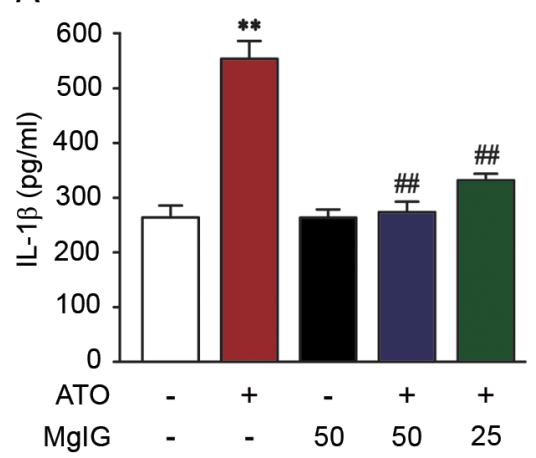

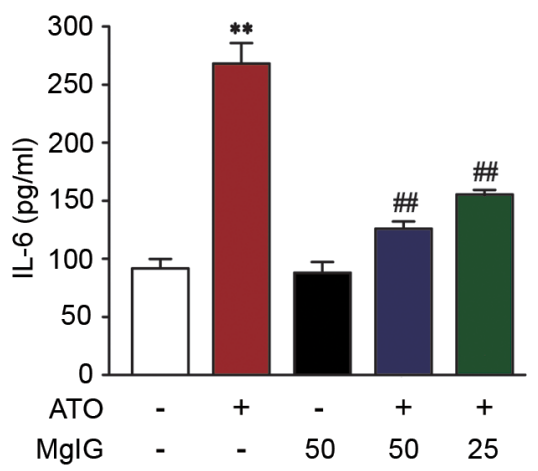

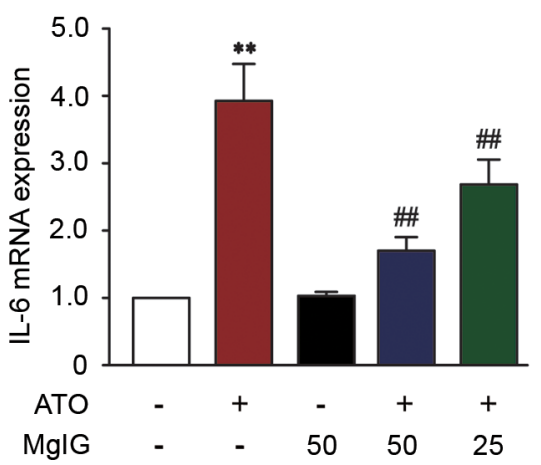

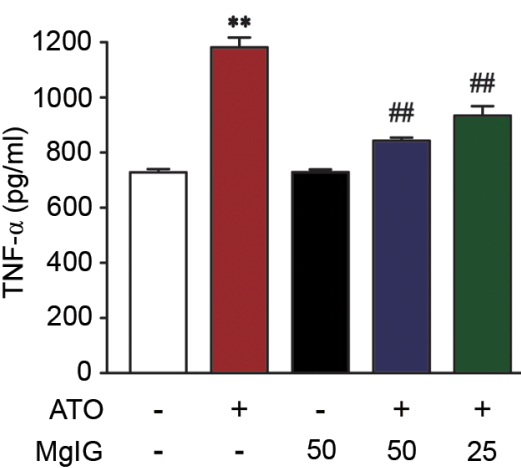

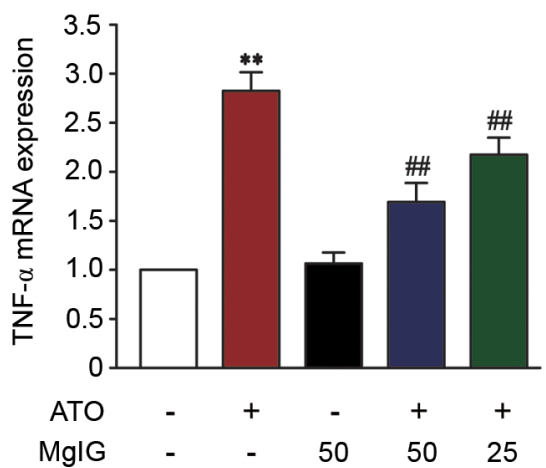

Figure 4. Effect of MgIG on expression levels of IL-1 $\beta$, IL-6 and TNF- $\alpha$. Expression levels of IL-1 $\beta$, IL- 6 and TNF- $\alpha$ were examined by (A) ELISA and (B) reverse transcription-quantitative PCR. Data are presented as the mean $\pm \mathrm{SEM}(\mathrm{n}=10) .{ }^{* *} \mathrm{P}<0.01 \mathrm{vs}$. CON, ${ }^{\#} \mathrm{P}<0.01 \mathrm{vs}$. ATO. MgIG, magnesium isoglycyrrhizinate; ATO, arsenic trioxide; $\mathrm{CON}$, control.

\section{Discussion}

Current cancer treatment methods include chemotherapy, surgery and radiotherapy. Traditional Chinese medicine and its components also show strong anti-tumor effects (52). ATO is a primary component in traditional Chinese medicine that is effective in the treatment of both newly diagnosed and relapsed patients with APL (53). However, it can also lead to liver toxicity, which limits its clinical application in cancer treatment $(54,55)$. Thus, it is important to find a suitable ATO antidote.

Licorice is an herbal medicine and natural sweetener that is widely used in China and contains numerous active ingredients; its extracts exhibit anti-viral, anti-bacterial, anti-inflammatory, anti-cancer and anti-oxidant activity (56). MgIG is a 4th-generation glycyrrhizic acid agent extracted from licorice by alkali isomerization catalysis; it is currently used as a liver-protecting agent in clinical treatment (57). The therapeutic effects of MgIG in the treatment of liver disease has been confirmed in liver disease models, including drug-induced and immune-mediated liver injury and fatty liver disease (58) The aim of the present study was to investigate the protective effect and potential mechanism of $\mathrm{MgIG}$ on liver injury induced by ATO.

Hepatotoxicity is caused by increased inflammatory cytokines, oxidative stress and apoptosis. This is a major drawback of adverse reactions of various anti-cancer and anti-tubercular drugs (59). Here, the activity of hepatic marker enzymes in serum significantly increased following treatment with ATO, which may be due to leakage of enzymes into the blood stream (60). MgIG significantly reverses increased ALT and AST activity in serum, indicating that $\mathrm{MgIG}$ restores ATO-induced liver injury (61). These results are associated with hepatotoxicity induced by ATO, which was confirmed here by histopathological examination. The histological sections of the liver were normal in the $\mathrm{CON}$ and $\mathrm{MgIG}$ groups, but ATO caused serious liver disease, including cellular necrosis, inflammatory cell infiltration, pyknotic nuclei and vacuolated hepatocytes. Slight hepatocyte swelling and bleeding were observed in the H-MgIG and L-MgIG groups, suggesting that pretreatment with MgIG diminished liver injury.

Oxidative stress is a result of the imbalance between ROS and antioxidants in the body and leads to oxidative damage of macromolecules; this has been implicated in the pathogenesis of numerous types of disease, including chronic kidney disease, atherosclerosis and Alzheimer's disease (62-65). The production of mitochondrial ROS is increased upon exposure to xenobiotics, especially ATO, which can overwhelm the antioxidant defense mechanism and damage cellular ingredients such as DNA, proteins and lipids $(66,67)$. Mitochondria are the central site for ROS generation and energy metabolism (68). Thus, uncontrolled overproduction of ROS can overwhelm the cellular antioxidant capacity and impair the mitochondria (69). Antioxidants inhibit oxidative stress via inhibiting production of ROS and improve the function of mitochondria (70). Therefore, antioxidants are a good therapeutic strategy for treatment of liver disorders in light of the key role of oxidative stress in liver disease (71).

The present study showed that exposure to ATO significantly increased ROS generation in hepatocytes compared 
A

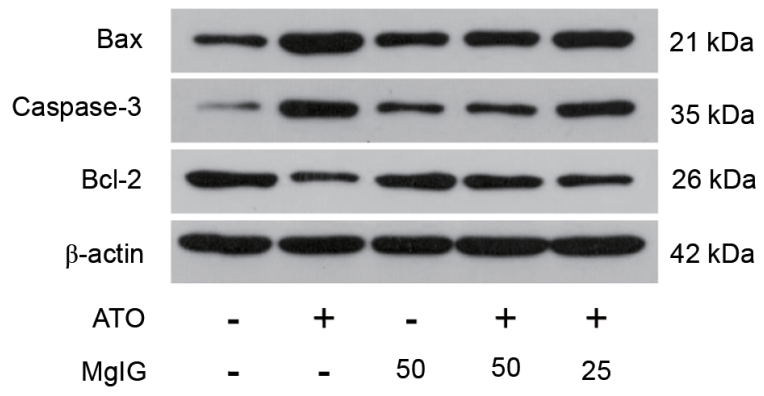

C

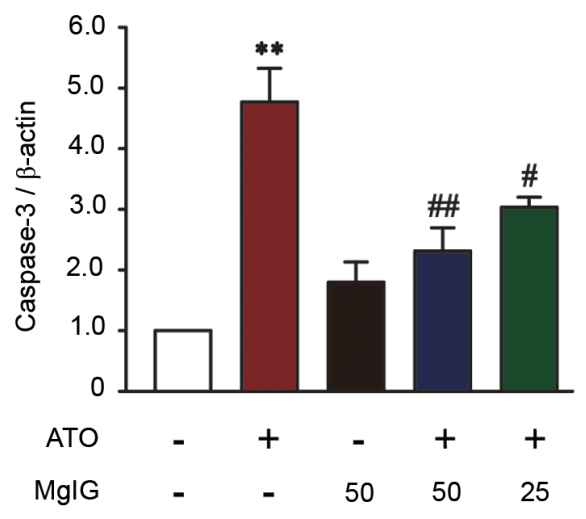

E

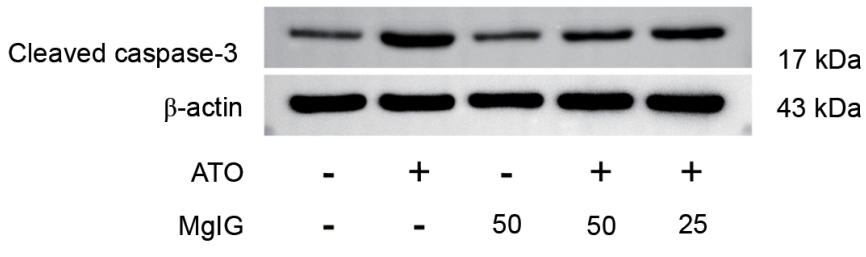

B

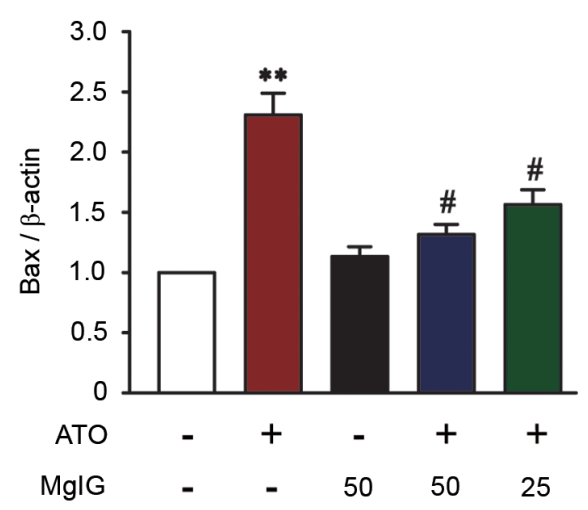

D

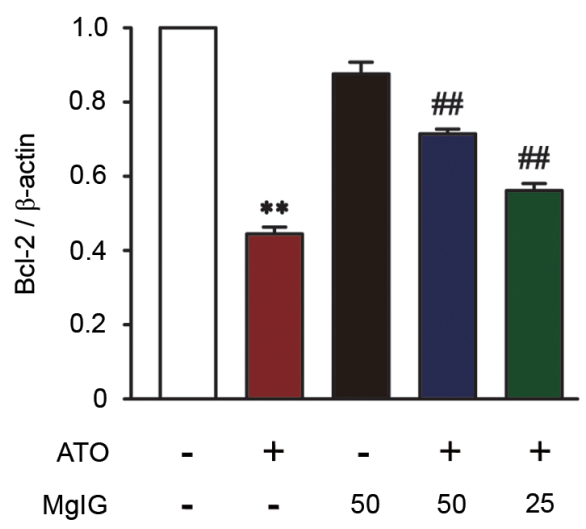

F

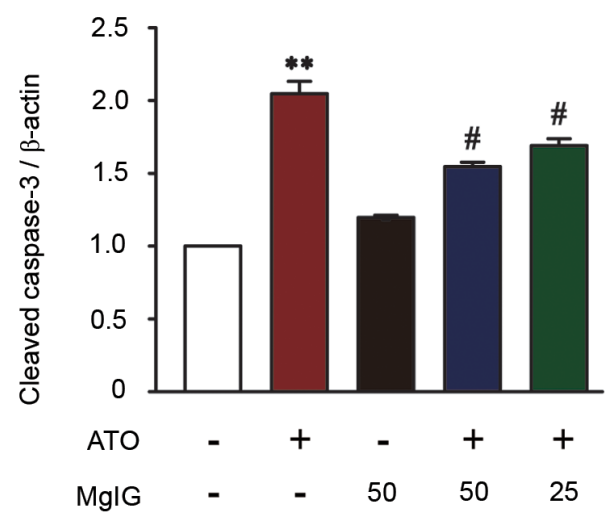

Figure 5. Effect of MgIG on expression of Bax, Bcl-2, caspase-3 and cleaved caspase-3. (A) Western blotting was used to determine the expression levels of Bax, Bcl-2 and caspase-3. Intensity of (B) Bax, (C) caspase-3 and (D) Bcl-2 was standardized to protein expression levels of $\beta$-actin. (E) Western blotting analysis was performed to determine expression of cleaved caspase-3. (F) Intensity of cleaved caspase-3 was standardized to the protein expression levels of $\beta$-actin. Data are presented as the mean \pm SEM $(n=3)$. ${ }^{* *} \mathrm{P}<0.01$ vs. CON, ${ }^{\#} \mathrm{P}<0.05$ and ${ }^{\# \#} \mathrm{P}<0.01$ vs. ATO. MgIG, magnesium isoglycyrrhizinate; ATO, arsenic trioxide; $\mathrm{CON}$, control.

with the CON group. The level of ROS in the ATO was notably attenuated by MgIG at both high and low doses. Antioxidant enzymes, such as SOD, CAT and GSH, are second line cellular defenses against oxidative liver injury (72-74). Changes in levels of these enzymes is an indirect method to evaluate the antioxidant-prooxidant condition in ATO (75). Their inactivation leads to further oxidative damage. In the present study,
MDA content increased gradually upon aggravation of liver damage. In recent years, the powerful antioxidant and free radical scavenging activity of MgIG have been extensively reported in in vitro experiments (76,77). Here, the antioxidant effect of MgIG was demonstrated using an animal model. There were notably increased levels of SOD, GSH and CAT following treatment with MgIG, along with decreased 

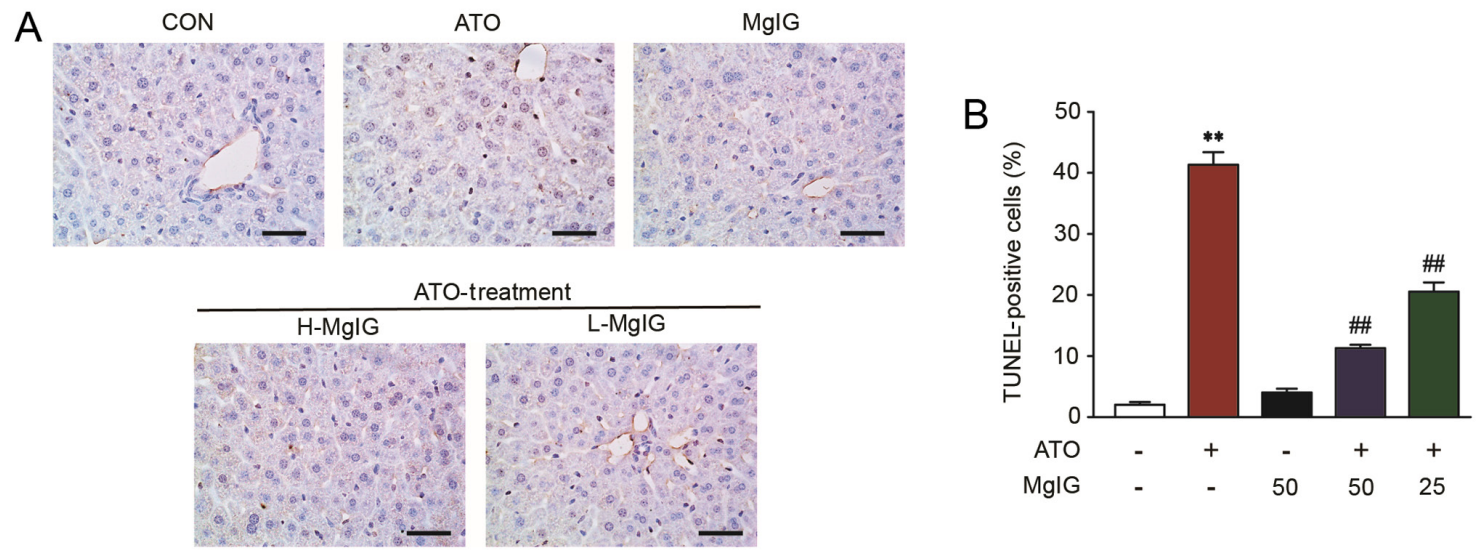

Figure 6. Effect of MgIG treatment on apoptosis, as detected by TUNEL staining. (A) Representative images of apoptotic cells. (B) Proportion of positive cells. Scale bar, $50 \mu \mathrm{m}$; magnification, $\mathrm{x} 400$. Data are presented as the mean $\pm \mathrm{SEM}(\mathrm{n}=10) .{ }^{* *} \mathrm{P}<0.01 \mathrm{vs}$. CON, ${ }^{\# \#} \mathrm{P}<0.01$ vs. ATO. MgIG, magnesium isoglycyrrhizinate; ATO, arsenic trioxide; CON, control; $\mathrm{H}-$, high; L-, low.

A

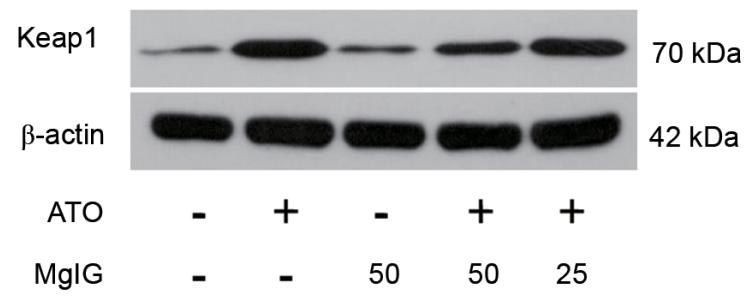

C

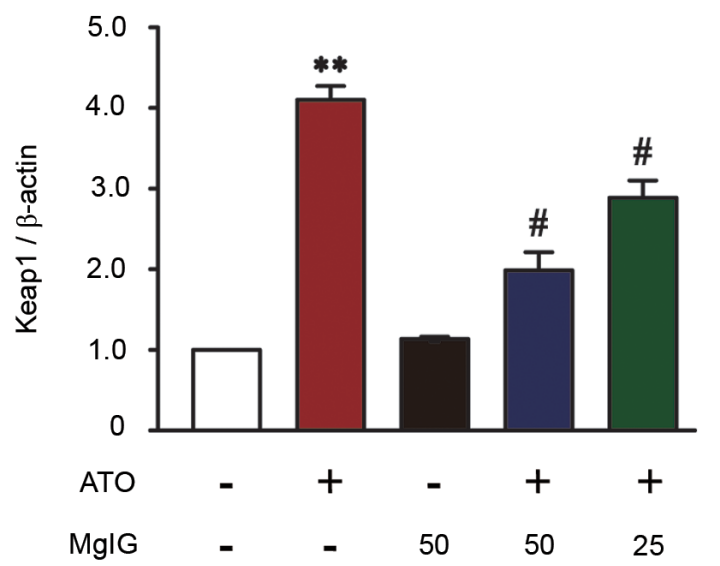

B

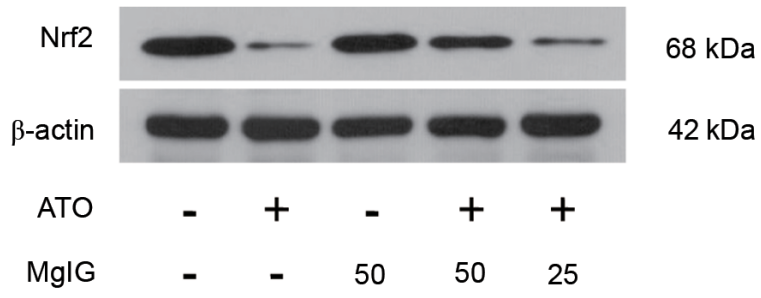

D

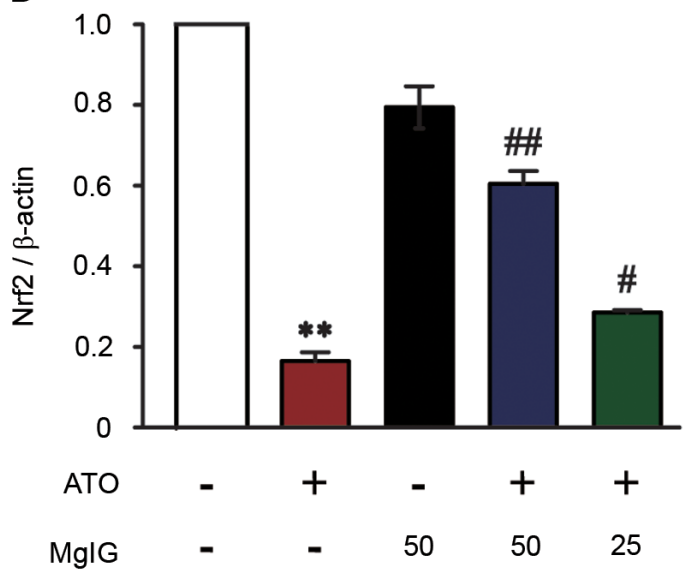

Figure 7. Effect of MgIG on Keap1-Nrf2 protein expression levels. (A) Western blotting was used to determine the expression of Keap1. (B) Western blotting was used to determine the expression of Nrf2. (C) Intensity of Keap1 was standardized to the protein expression levels of $\beta$-actin. (D) Intensity of Nrf2 was standardized to the protein expression levels of $\beta$-actin. Data are presented as the mean \pm SEM ( $=3$ ). ${ }^{* *} \mathrm{P}<0.01 \mathrm{vs}$. CON, ${ }^{\#} \mathrm{P}<0.05$ and ${ }^{\# \#} \mathrm{P}<0.01 \mathrm{vs}$. ATO. MgIG, magnesium isoglycyrrhizinate; Keap1, Kelch-like ECH-associated protein 1; Nrf2, nuclear factor erythroid 2-related factor 2; CON, control; ATO, arsenic trioxide.

MDA content, which demonstrated that MgIG alleviated ATO-induced oxidative damage. These data suggested that MgIG suppressed ATO-induced hepatic ROS overproduction.

Activation of the antioxidant system requires inhibition of the inflammatory response and cell apoptosis (78). Inflammatory factors are activated in response to toxic damage via ATO-induced hepatotoxicity (79). One of the marks of the inflammatory response is the production of pro-inflammatory mediators, which are needed to repair injured tissue. IL-1 $\beta$, IL-6 and TNF- $\alpha$ are key pro-inflammatory factors of the immune response; they primarily serve pro-inflammatory roles that aggravate further tissue damage (80). Pro-inflammatory cytokines, such as IL-1 $\beta$, IL- 6 and TNF- $\alpha$, exhibited enhanced expression in the liver, which confirmed ATO-induced 


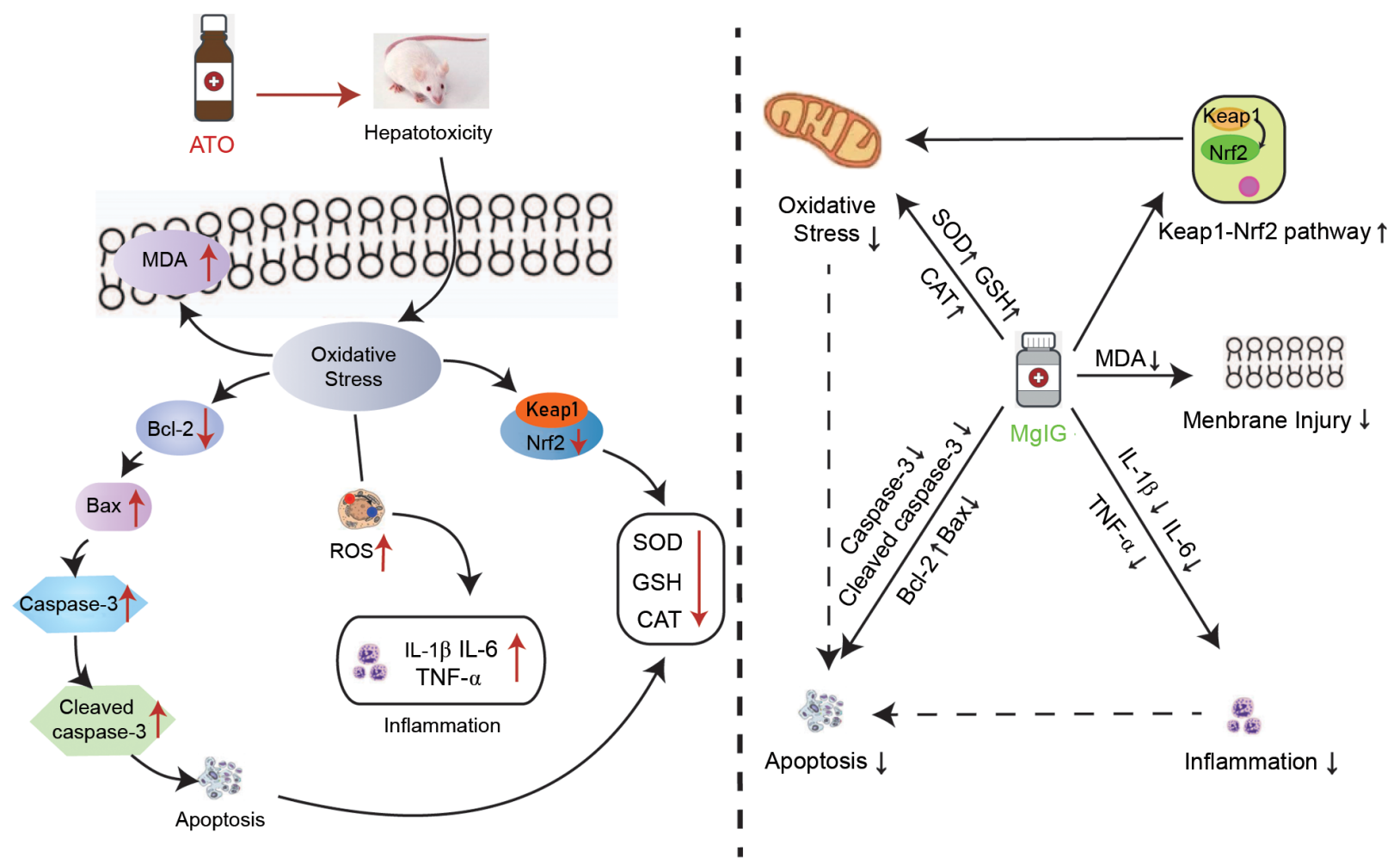

Figure 8. Mechanism of the protective effect of MgIG against hepatotoxicity induced by ATO. MgIG, magnesium isoglycyrrhizinate; ATO, arsenic trioxide; Keap1, Kelch-like ECH-associated protein 1; Nrf2, nuclear factor erythroid 2-related factor 2; CAT, catalase; SOD, superoxide dismutase; GSH, glutathione; MDA, malonaldehyde; ROS, reactive oxygen species.

hepatotoxicity. MgIG inhibited the expression levels of inflammatory cytokines. Oxidative stress is positively associated with cell apoptosis (81).

Apoptosis is programmed cell death that leads to death or morphological changes in the cell to replace older cells with newer cells. Apoptosis involves a series of active death processes and is regulated by multiple genes associated with the pro-apoptotic Bax subfamily and the anti-apoptotic Bcl-2 subfamily $(82,83)$. Caspase- 3 is the 'effector' protease in the apoptosis cascade and is one of the primary executors of apoptosis (84). One of the best-known markers of apoptosis is proteolytic cleavage of pro-caspase- 3 into its active form, caspase-3 (85). When cells undergo apoptosis, caspase-3 is activated to cleaved caspase-3, which promotes apoptosis (86). Here, ATO caused excessive ROS production and promoted apoptosis. ATO is cytotoxic and causes liver injury; it also decreases cell activity and increases apoptosis $(35,87)$. The increase in expression levels of Bax in the ATO group, concomitant with a decrease in the expression levels of Bcl-2, demonstrated apoptotic events in ATO mice; however, there were significant improvements following treatment with MgIG. Compared with the ATO-induced hepatotoxicity group, MgIG notably decreased the expression levels of caspase-3 and cleaved caspase- 3 and the number of TUNEL-positive cells in the liver tissue. These biological indices suggested that MgIG treatment ameliorated liver injury induced by ATO.

The exact mechanism of ATO-induced hepatotoxicity remains unclear, but it has been reported that reactive metabolites decrease Nrf2 levels, induce ROS production and inhibit an endogenous antioxidant defense system that results in severe oxidative stress $(88,89)$. Nrf2 is a key antioxidant transcription factor that is recognized as a primary transcriptional regulation pathway involved in the metabolism and detoxification of toxic substances $(90,91)$. The mechanism by which ATO inhibits Nrf2 expression may involve accelerating Nrf2 degradation by promoting Keap1 protein expression levels (92). Zhao et al (41) demonstrated that activating Nrf2 and expression levels of Nrf2-regulated antioxidant enzymes and detoxification protects $\mathrm{HaCaT}$ cells from ATO-induced cytotoxicity and apoptosis. In the present study, the decrease in Nrf2 content induced by ATO indicates that excessive oxidative stress consumes a large amount of Nrf2 or disrupts homeostasis between Nrf2 production and degradation. This damages the antioxidant defense system and constantly aggravates injury unless alleviated. However, MgIG maintained high levels of Nrf2 in the liver and protected the antioxidative defense system to attenuate oxidative stress and prevent ATO-induced liver injury.

Here, MgIG restrained ATO-mediated hepatotoxicity by inhibiting oxidative stress, inflammation and apoptosis (Fig. 8). The potential molecular mechanism of MgIG' hepatoprotection may be due to activation of the Keap1-Nrf2 signaling pathway. Overall, MgIG exhibited a protective potential effect on ATO-induced hepatotoxicity. Future experiments are needed to delineate the specific mechanism involved in this protective function. 


\section{Acknowledgements}

Not applicable.

\section{Funding}

The present study was supported by the Research Foundation of Administration of Traditional Chinese Medicine of Hebei Province, China (grant no. 2020188), Research Foundation of Hebei University of Chinese Medicine (grant no. KTZ2019041) and the open projects of Hebei Key Laboratory of Integrative Medicine on Liver-kidney Patterns (grant no. B 201907).

\section{Availability of data and materials}

The datasets used and/or analyzed during the current study are available from the corresponding author on reasonable request.

\section{Authors' contributions}

$\mathrm{XH}, \mathrm{LC}$ and JS contributed to the design of the experiments. ML, BZ, YaL, JZ and CD performed experiments and obtained the data. YiL, XC and PL analyzed the data. ML and PL wrote the manuscript. ML, LC and JZ revised the manuscript. ML and XH confirm the authenticity of all the raw data. All authors read and approved the final manuscript.

\section{Ethics approval and consent to participate}

All operating procedures regarding experimental animals were approved by the Ethics Committee for Animal Experiments of Hebei University of Chinese Medicine (approval no. DWLL2020005).

\section{Patient consent for publication}

Not applicable.

\section{Competing interests}

The authors declare that they have no competing interests.

\section{References}

1. Centeno JA, Mullick FG, Martinez L, Page NP, Gibb H, Longfellow D, Thompson C and Ladich ER: Pathology related to chronic arsenic exposure. Environ Health Persp 110 (Suppl 5): S883-S886, 2002.

2. Emadi A and Gore SD: Arsenic trioxide-An old drug rediscovered. Blood Rev 24: 191-199, 2010.

3. Gore SD, Gojo I, Sekeres MA, Morris L, Devetten M, Jamieson K, Redner RL, Arceci R, Owoeye I, Dauses T, et al: Single cycle of arsenic trioxide-based consolidation chemotherapy spares anthracycline exposure in the primary management of acute promyelocytic leukemia. J Clin Oncol 28: 1047-1053, 2010.

4. Antman KH: Introduction: The history of arsenic trioxide in cancer therapy. Oncologist 6 (Suppl 2): S1-S2, 2001.

5. Abaza Y, Kantarjian H, Garcia-Manero G, Estey E, Borthakur G, Jabbour E, Faderl S, O'Brien S, Wierda W, Pierce S, et al Long-term outcome of acute promyelocytic leukemia treated with all trans-retinoic acid, arsenic trioxide, and gemtuzumab. Blood 129: 1275-1283, 2017.
6. Breccia M and Lo-Coco F: Arsenic trioxide for management of acute promyelocytic leukemia: Current evidence on its role in front-line therapy and recurrent disease. Expert Opin Pharmacother 13: 1031-1043, 2012.

7. Iland HJ, Bradstock K, Supple SG, Catalano A, Collins M, Hertzberg M, Browett P, Grigg A, Firkin F, Hugman A, et al: All-trans-retinoic acid, idarubicin, and IV arsenic trioxide as initial therapy in acute promyelocytic leukemia (APML4). Blood 120: 1570-1580; quiz 1752, 2012.

8. Lo-Coco F, Avvisati G, Vignetti M, Thiede C, Orlando SM, Iacobelli S, Ferrara F, Fazi P, Cicconi L, Di Bona E, et al: Retinoic acid and arsenic trioxide for acute promyelocytic leukemia. N Engl J Med 369: 111-121, 2013.

9. Zhang X, Jia S, Yang S, Yang Y, Yang T and Yang Y: Arsenic trioxide induces $\mathrm{G} 2 / \mathrm{M}$ arrest in hepatocellular carcinoma cells by increasing the tumor suppressor PTEN expression. J Cell Biochem 113: 3528-3535, 2012.

10. Walker AM, Stevens JJ, Ndebele $K$ and Tchounwou PB: Evaluation of arsenic trioxide potential for lung cancer treatment: Assessment of apoptotic mechanisms and oxidative damage. J Cancer Sci Ther 8: 1-9, 2016.

11. Messarah M, Klibet F, Boumendjel A, Abdennour C, Bouzerna N, Boulakoud MS and El Feki A: Hepatoprotective role and antioxidant capacity of selenium on arsenic-induced liver injury in rats. Exp Toxicol Pathol 64: 167-174, 2012.

12. Miller WH Jr, Schipper HM, Lee JS, Singer J and Waxman S: Mechanisms of action of arsenic trioxide. Cancer Res 62: 3893-3903, 2002.

13. Jin W, Xue Y, Xue Y, Han X, Song Q, Zhang J, Li Z, Cheng J, Guan S, Sun S and Chu L: Tannic acid ameliorates arsenic trioxide-induced nephrotoxicity, contribution of NF- $\kappa \mathrm{B}$ and Nrf2 pathways. Biomed Pharmacother 126: 110047, 2020.

14. Liu Y, Liang Y, Zheng B, Chu L, Ma D, Wang H, Chu X and Zhang J: Protective effects of crocetin on arsenic trioxide-induced hepatic injury: Involvement of suppression in oxidative stress and inflammation through activation of Nrf2 signaling pathway in rats. Drug Des Dev Ther 14: 1921-1931, 2020.

15. Li M, Liu P, Xue Y, Liang Y, Shi J, Han X, Zhang J, Chu X and Chu L: Tannic acid attenuates hepatic oxidative stress, apoptosis and inflammation by activating the Keap1Nrf2/ARE signaling pathway in arsenic trioxide-toxicated rats. Oncol Rep 44: 2306-2316, 2020

16. Benramdane L, Accominotti M, Fanton L, Malicier D and Vallon JJ: Arsenic speciation in human organs following fatal arsenic trioxide poisoning-a case report. Clin Chem 45: 301-306, 1999.

17. Xu M, Rui D, Yan Y, Xu S, Niu Q, Feng G, Wang Y, Li S and Jing M: Oxidative damage induced by arsenic in mice or rats: A systematic review and meta-analysis. Biol Trace Elem Res 176: 154-175, 2017.

18. Valko M, Morris H and Cronin MT: Metals, toxicity and oxidative stress. Curr Med Chem 12: 1161-1208, 2005.

19. Alam MF, Khan G, Safhi MM, Alshahrani S, Siddiqui R, Sivagurunathan Moni S and Anwer T: Thymoquinone ameliorates doxorubicin-induced cardiotoxicity in swiss albino mice by modulating oxidative damage and cellular inflammation. Cardiol Res Pract 2018: 1483041, 2018.

20. Kim SY, Park C, Jang HJ, Kim BO, Bae HW, Chung IY, Kim ES and Cho YH: Antibacterial strategies inspired by the oxidative stress and response networks. J Microbiol 57: 203-212, 2019.

21. Sies H and Jones DP: Reactive oxygen species (ROS) as pleiotropic physiological signalling agents. Nat Rev Mol Cell Biol 21: 363-383, 2020.

22. Mortezaee $\mathrm{K}$ and Khanlarkhani N: Melatonin application in targeting oxidative-induced liver injuries: A review. J Cell Physiol 233: 4015-4032, 2018.

23. Grossini E, Bellofatto K, Farruggio S, Sigaudo L, Marotta P, Raina G, De Giuli V, Mary D, Pollesello P, Minisini R, et al: Levosimendan inhibits peroxidation in hepatocytes by modulating apoptosis/autophagy interplay. PLoS One 10: e0124742, 2015 .

24. Weiskirchen R and Tacke F: Relevance of autophagy in parenchymal and non-parenchymal liver cells for health and disease. Cells 8: 16, 2019.

25. Barrera C, Valenzuela R, Rincon MA, Espinosa A, Echeverria F, Romero N, Gonzalez-Mañan D and Videla LA: Molecular mechanisms related to the hepatoprotective effects of antioxidant-rich extra virgin olive oil supplementation in rats subjected to short-term iron administration. Free Radic Biol Med 126: 313-321, 2018. 
26. Chayapong J, Madhyastha H, Madhyastha R, Nurrahmah QI, Nakajima Y, Choijookhuu N, Hishikawa Y and Maruyama M: Arsenic trioxide induces ROS activity and DNA damage, leading to $G_{0} / G_{1}$ extension in skin fibroblasts through the ATM-ATR-associated Chk pathway. Environ Sci Pollut Res Int 24: 5316-5325, 2017.

27. Nili-Ahmadabadi A, Alibolandi P, Ranjbar A, Mousavi L, Nili-Ahmadabadi H,Larki-Harchegani A, Ahmadimoghaddam D and Omidifar N: Thymoquinone attenuates hepatotoxicity and oxidative damage caused by diazinon: An in vivo study. Res Pharm Sci 13: 500-508, 2018.

28. Hu JP, Zhao XP, Ma XZ, Wang Y and Zheng LJ: Effects of cigarette smoke on aerobic capacity and serum MDA content and SOD activity of animal. Int J Clin Exp Med 7: 4461-4465, 2014.

29. Shafik NM and El Batsh MM: Protective effects of combined selenium and punica granatum treatment on some inflammatory and oxidative stress markers in arsenic-induced hepatotoxicity in rats. Bio Trace Elem Res 169: 121-128, 2016.

30. Sharanek A, Burban A, Ciriacim N and Guillouzo A: Pro-inflammatory cytokines enhance dilatation of bile canaliculi caused by cholestatic antibiotics. Toxicol In Vitro 58: 51-59, 2019.

31. Tu C, Gao D, Li XF, Li CY, Li RS, Zhao YL, Li N, Jia GL, Pang JY, Cui HR, et al: Inflammatory stress potentiates emodin-induced liver injury in rats. Front Pharmacol 6: 233, 2015.

32. Zhang J, Zhang Y, Wang W, Li C and Zhang Z: Double-sided personality: Effects of arsenic trioxide on inflammation. Inflammation 41: 1128-1134, 2018.

33. Dugo EB, Yedjou CG, Stevens JJ and Tchounwou PB: Therapeutic potential of arsenic trioxide (ATO) in treatment of hepatocellular carcinoma: Role of oxidative stress in ATO-induced apoptosis. Ann Clin Pathol 5: 1101, 2017.

34. Abouzied MM, Eltahir HM, Abdel Aziz MA, Ahmed NS, Abd El-Ghany AA, Abd El-Aziz EA and Abd El-Aziz HO: Curcumin ameliorate DENA-induced HCC via modulating TGF-beta, AKT, and caspase- 3 expression in experimental rat model. Tumor Bio 36: 1763-1771, 2015.

35. Adams JM and Cory S: The Bcl-2 apoptotic switch in cancer development and therapy. Oncogene 26: 1324-1337, 2007.

36. Carthy CM, Yanagawa B, Luo H, Granville DJ, Yang D, Cheung P. Cheung C, Esfandiarei M, Rudin CM, Thompson CB, et al: $\mathrm{Bcl}-2$ and $\mathrm{Bcl}-\mathrm{xL}$ overexpression inhibits cytochrome $\mathrm{c}$ release, activation of multiple caspases, and virus release following coxsackievirus B3 infection. Virology 313: 147-157, 2003.

37. Miltonprabu S, Sumedha NC and Senthilraja P: Diallyl trisulfide, a garlic polysulfide protects against As-induced renal oxidative nephrotoxicity, apoptosis and inflammation in rats by activating the Nrf2/ARE signaling pathway. Int Immunopharmacol 50: $107-120,2017$

38. Chen X, Xue H, Fang W, Chen K, Chen S, Yang W, Shen T, Chen X, Zhang P and Ling W: Adropin protects against liver injury in nonalcoholic steatohepatitis via the Nrf2 mediated antioxidant capacity. Redox Biol 21: 101068, 2019.

39. Mitsuishi Y, Motohashi H and Yamamoto M: The Keap1-Nrf2 system in cancers: Stress response and anabolic metabolism. Front Oncol 2: 200, 2012.

40. Sabouny R, Fraunberger E, Geoffrion M, Ng AC, Baird SD, Screaton RA, Milne R, McBride HM and Shutt TE: The Keap1-Nrf2 stress response pathway promotes mitochondrial hyperfusion through degradation of the mitochondrial fission protein drp1. Antioxid Redox Sign 27: 1447-1459, 2017.

41. Zhao R, Yang B, Wang L, Xue P, Deng B, Zhang G, Jiang S, Zhang M, Liu M, Pi J and Guan D: Curcumin protects human keratinocytes against inorganic arsenite-induced acute cytotoxicity through an NRF2-dependent mechanism. Oxid Med Cell Longev 2013: 412576, 2013.

42. Wu Z, Zhang Y, Song T, Song Q, Zhang Y, Zhang X, Han X, Zhang J and Chu L: Magnesium isoglycyrrhizinate ameliorates doxorubicin-induced acute cardiac and hepatic toxicity via anti-oxidant and anti-apoptotic mechanisms in mice. Exp Ther Med 15: 1005-1012, 2018.

43. Zhang JC, Zheng GF, Wu MX, Wu JW, Ouyang LY and Liu XQ: Effect of magnesium isoglycyrrhizinate on PLA2 during liver tissue injury following limb ischemia/reperfusion in rats. Zhonghua Gan Zang Bing Za Zhi 20: 537-541, 2012 (In Chinese).

44. Sun L, Shen J, Pang X, Lu L, Mao Y and Zeng M: Phase I safety and pharmacokinetic study of magnesium isoglycyrrhizinate after single and multiple intravenous doses in chinese healthy volunteers. J Clin Pharmacol 47: 767-773, 2007.
45. Ma D, Zhang J, Zhang Y, Zhang X, Han X, Song T, Zhang Y and Chu L: Inhibition of myocardial hypertrophy by magnesium isoglycyrrhizinate through the TLR4/NF- $\mathrm{BB}$ signaling pathway in mice. Int Immunopharmacol 55: 237-244, 2018

46. Xue Y, Li M, Xue Y, Jin W, Han X, Zhang J, Chu X, Li Z and Chu L: Mechanisms underlying the protective effect of tannic acid against arsenic trioxideinduced cardiotoxicity in rats: Potential involvement of mitochondrial apoptosis. Mol Med Rep 22: 4663-4674, 2020.

47. Jiang W, Chen Q, Li P, Lu Q, Pei X, Sun Y, Wang G and Hao K: Magnesium Isoglycyrrhizinate attenuates lipopolysaccharide-induced depressive-like behavior in mice. Biomed Pharmacother 86: 177-184, 2017.

48. Birari LA, Mahajan UB, Patil KR, Patil DD, Bagul NA, Belemkar S, Goyal SN, Ojha S and Patil CR: Aloin protects against arsenic trioxide-induced myocardial membrane damage and release of inflammatory cytokines. Naunyn Schmiedebergs Arch Pharmacol 393: 1365-1372, 2020.

49. Knuckles TL, Buntz JG, Paffett M, Channell M, Harmon M, Cherng T, Lucas SN, McDonald JD, Kanagy NL and Campen MJ: Formation of vascular S-nitrosothiols and plasma nitrates/nitrites following inhalation of diesel emissions. J Toxicol Environ Health A 74: 828-837, 2011.

50. Thapa BR and Walia A: Liver function tests and their interpretation. Indian J Pediatr 74: 663-671, 2007.

51. Livak KJ and Schmittgen TD: Analysis of relative gene expres-sion data using real-time quantitative PCR and the 2(-Delta Delta C(T)) method. Methods 25: 402-408, 2001.

52. Hede K: Chinese folk treatment reveals power of arsenic to treat cancer, new studies under way. J Natl Cancer Inst 99: 667-668, 2007.

53. Qu W, Cheng L, Dill AL, Saavedra JE, Hong SY, Keefer LK and Waalkes MP: Nitric oxide donor, V-PROLI/NO, provides protection against arsenical induced toxicity in rat liver cells: Requirement for Cypla1. Chem Biol Interact 193: 88-96, 2011.

54. Mathews V, Desire S, George B, Lakshmi KM, Rao JG, Viswabandya A, Bajel A, Srivastava VM, Srivastava A and Chandy M: Hepatotoxicity profile of single agent arsenic trioxide in the treatment of newly diagnosed acute promyelocytic leukemia, its impact on clinical outcome and the effect of genetic polymorphisms on the incidence of hepatotoxicity. Leukemia 20: 881-883, 2006

55. Ducas RA, Seftel MD, Ducas J and Seifer C: Monomorphic ventricular tachycardia caused by arsenic trioxide therapy for acute promyelocytic leukaemia. J R Coll Physicians Edinb 41: 117-118, 2011.

56. Wang ZF, Liu J, Yang YG and Zhu HL: A review: The anti-inflammatory, anticancer and antibacterial properties of four kinds of licorice flavonoids isolated from licorice. Curr Med Chem 27: 1997-2011, 2020

57. Chen KJ, Chen WY, Chen X, Jia YM, Peng GQ and Chen L: Increased elimination of paclitaxel by magnesium isoglycyrrhizinate in epithelial ovarian cancer patients treated with paclitaxel plus cisplatin: A pilot clinical study. Eur J Drug Metab Pharmacokinet 39: 25-31, 2014

58. Lv J, Xiao Q, Chen Y, Fan X, Liu X, Liu F, Luo G, Zhang B and Wang S: Effects of magnesium isoglycyrrhizinate on AST, ALT, and serum levels of Th1 cytokines in patients with allo-HSCT. Int Immunopharmacol 46: 56-61, 2017.

59. Cetin A, Kaynar L, Kocyigit I, Hacioglu SK, Saraymen R, Ozturk A, Sari I and Sagdic O: Role of grape seed extract on methotrexate induced oxidative stress in rat liver. Am J Chin Med 36: 861-872, 2008

60. Kim WR, Flamm SL, Di Bisceglie AM, Bodenheimer HC and Public Policy Committee of the American association for the study of liver disease: Serum activity of alanine aminotransferase (ALT) as an indicator of health and disease. Hepatology 47: 1363-1370, 2008

61. Yang RZ, Park S, Reagan WJ, Goldstein R, Zhong S, Lawton M, Rajamohan F, Qian K, Liu L and Gong DW: Alanine aminotransferase isoenzymes: Molecular cloning and quantitative analysis of tissue expression in rats and serum elevation in liver toxicity. Hepatology 49: 598-607, 2009.

62. Sifuentes-Franco S,Pacheco-Moises FP,Rodriguez-CarrizalezAD and Miranda-Diaz AG: The role of oxidative stress, mitochondrial function, and autophagy in diabetic polyneuropathy. J Diabetes Res 2017: 1673081, 2017.

63. Daenen K, Andries A, Mekahli D, Van Schepdael A, Jouret F and Bammens B: Oxidative stress in chronic kidney disease. Pediatr Nephrol 34: 975-991, 2019. 
64. Förstermann U, Xia N and Li H: Roles of vascular oxidative stress and nitric oxide in the pathogenesis of atherosclerosis. Circ Res 120: 713-735, 2017.

65. Butterfield DA and Halliwell B: Oxidative stress, dysfunctional glucose metabolism and Alzheimer disease. Nat Rev Neurosci 20 : $148-160,2019$.

66. He JL, Dong XH, Li ZH, Wang XY, Fu ZA and Shen N: Pterostilbene inhibits reactive oxygen species production and apoptosis in primary spinal cord neurons by activating autophagy via the mechanistic target of rapamycin signaling pathway. Mol Med Rep 17: 4406-4414, 2018

67. Haga N, Fujita N and Tsuruo T: Involvement of mitochondrial aggregation in arsenic trioxide (As2O3)-induced apoptosis in human glioblastoma cells. Cancer Sci 96: 825-833, 2005.

68. Hosseini MJ, Shaki F, Ghazi-Khansari M and Pourahmad J: Toxicity of copper on isolated liver mitochondria: Impairment at complexes I, II, and IV leads to increased ROS production. Cell Biochem Biophys 70: 367-381, 2014.

69. Ortiz M, Soto-Alarcon SA, Orellana P, Espinosa A, Campos C, López-Arana S, Rincón MA, Illesca P, Valenzuela R and Videla LA: Suppression of high-fat diet-induced obesity-associated liver mitochondrial dysfunction by docosahexaenoic acid and hydroxytyrosol co-administration. Dig Liver Dis 52: 895-904, 2020

70. Hernandez-Rodas MC, Valenzuela R, Echeverria F, Rincón-Cervera MÁ, Espinosa A, Illesca P, Muñoz P, Corbari A, Romero N, Gonzalez-Mañan D and Videla LA: Supplementation with docosahexaenoic acid and extra virgin olive oil prevents liver steatosis induced by a high-fat diet in mice through PPAR-o and Nrf2 upregulation with concomitant SREBP-1c and NF-kB downregulation. Mol Nutr Food Res 61: 2017.

71. Kim SH and Kim H: Inhibitory effect of astaxanthin on oxidative stress-induced mitochondrial dysfunction-A mini-review. Nutrients 10: 1137, 2018.

72. Santos C, Pires Mdos A, Santos D and Payan-Carreira R: Distribution of superoxide dismutase 1 and glutathione peroxidase 1 in the cyclic canine endometrium. Theriogenology 86 738-748, 2016

73. Durak I, Yurtarslanl Z, Canbolat O and Akyol O: A methodological approach to superoxide dismutase (SOD) activity assay based on inhibition of nitroblue tetrazolium (NBT) reduction. Clin Chim Acta 214: 103-104, 1993.

74. Mates JM: Effects of antioxidant enzymes in the molecular control of reactive oxygen species toxicology. Toxicology 153: 83-104, 2000.

75. Shen H, Niu Q, Xu M, Rui D, Xu S, Feng G, Ding Y, Li S and Jing M: Factors affecting arsenic methylation in arsenic-exposed humans: A systematic review and meta-analysis. Int J Environ Res Public Health 13: 205, 2016.

76. Xie C, Li X, Zhu J, Wu J, Geng S and Zhong C: Magnesium isoglycyrrhizinate suppresses LPS-induced inflammation and oxidative stress through inhibiting NF- $\mathrm{B}$ and MAPK pathways in RAW264.7 cells. Bioorg Med Chem 27: 516-524, 2019.

77. Yang YZ, Liu ZH, Wang SC, Zhang XQ, Xu HJ, Yang L and Kong LD: Magnesium isoglycyrrhizinate alleviates fructose-induced liver oxidative stress and inflammatory injury through suppressing NOXs. Eur J Pharmacol 883: 173314, 2020.

78. Zheng Y, Tao S, Lian F, Chau BT, Chen J, Sun G, Fang D, Lantz RC and Zhang DD: Sulforaphane prevents pulmonary damage in response to inhaled arsenic by activating the Nrf2-defense response. Toxicol Appl Pharm 265: 292-299, 2012.
79. Islam LN, Nabi AH, Rahman MM and Zahid MS: Association of respiratory complications and elevated serum immunoglobulins with drinking water arsenic toxicity in human. J Environ Sci Health A Tox Hazard Subst Environ Eng 42: 1807-1814, 2007.

80. Zhang JX, Xing JG, Wang LL, Jiang HL, Guo SL and Liu R: Luteolin inhibits fibrillary $\beta$-amyloid ${ }_{1-40}$-induced inflammation in a human blood-brain barrier model by suppressing the p38 MAPK-Mediated NF- $\kappa$ B signaling pathways. Molecules 22: 334 2017.

81. Bai J and Meng Z: Effects of sulfur dioxide on apoptosis-related gene expressions in lungs from rats. Regul Toxicol Pharmacol 43: 272-279, 2005.

82. Robertson JD and Orrenius S: Molecular mechanisms of apoptosis induced by cytotoxic chemicals. Crit Rev Toxicol 30: 609-627, 2000

83. Yang LJ and Wang WL: Preparation of monoclonal antibody against apoptosis-associated antigens of hepatoma cells by subtractive immunization. World J Gastroenterol 8: 808-814, 2002.

84. Van Opdenbosch N and Lamkanfi M: Caspases in cell death, inflammation, and disease. Immunity 50: 1352-1364, 2019.

85. Rotschafer SE, Allen-Sharpley MR and Cramer KS: Axonal cleaved caspase-3 regulates axon targeting and morphogenesis in the developing auditory brainstem. Front Neural Circuits 10: 84, 2016.

86. Bernard A, Chevrier S, Beltjens F, Dosset M, Viltard E, Lagrange A, Derangère V, Oudot A, Ghiringhelli $\mathrm{F}$, Collin B, et al: Cleaved caspase-3 transcriptionally regulates angiogenesis-promoting chemotherapy resistance. Cancer Res 79: 5958-5970, 2019.

87. Han B, Zhou G, Zhang Q, Zhang J, Wang X, Tang W and Kakudo K: Effect of arsenic trioxide (ATO) on human lung carcinoma PG cell line: ATO induced apoptosis of PG cells and decreased expression of Bcl-2, Pgp. J Exp Ther Oncol 4: 335-342, 2004.

88. Yao P, Nussler A, Liu L, Hao L, Song F, Schirmeier A and Nussler N: Quercetin protects human hepatocytes from ethanol-derived oxidative stress by inducing heme oxygenase-1 via the MAPK/Nrf2 pathways. J Hepatol 47: 253-261, 2007.

89. Wu KC, Liu J and Klaassen CD: Role of Nrf2 in preventing ethanol-induced oxidative stress and lipid accumulation. Toxicol Appl Pharm 262: 321-329, 2012.

90. Lee CS, Ho DV and Chan JY: Nuclear factor-erythroid 2-related factor 1 regulates expression of proteasome genes in hepatocytes and protects against endoplasmic reticulum stress and steatosis in mice. FEBS J 280: 3609-3620, 2013.

91. Lee JM, Li J, Johnson DA, Stein TD, Kraft AD, Calkins MJ, Jakel RJ and Johnson JA: Nrf2, a multi-organ protector? FASEB J 19: 1061-1066, 2005.

92. Copple IM, Goldring CE, Kitteringham NR and Park BK: The keap1-nrf2 cellular defense pathway: Mechanisms of regulation and role in protection against drug-induced toxicity. Handb Exp Pharmacol 233-266, 2010

This work is licensed under a Creative Commons Attribution-NonCommercial-NoDerivatives 4.0 International (CC BY-NC-ND 4.0) License. 